\title{
Research of Status and Prospect of Virtual Instrument Technology
}

\author{
Li Wang ${ }^{\text {a }}$ Zhaohua Wang \\ Department of Energy Engineering, Yulin University, Yulin 719000, Shaanxi, China \\ a278116312@qq.com
}

Keywords: virtual instrument, traditional instruments, LabVIEW

Abstract: This paper first introduces the research status of virtual instrument technology research, starting from three aspects of automation level, real-time monitoring function and virtual instrument in the field of education, then explores the future direction of development on the basis of the virtual instrument technology, and hopes to further promote virtual instrument technology upgrade.

\section{Introduction}

Virtual instrument gradually has replaced the traditional instruments used in industrial production and measurement increasingly demonstrated its important role due to the powerful advantages of its combination of hardware and software [1-2]. Virtual instrument has the advantages of real-time and accuracy in the field of monitoring and measurement; virtual instrument also has the advantage of openness and flexibility in the field of education [3].

\section{Technical research status quo of virtual instrument}

\subsection{The automation level of virtual instrument gradually increases}

Research capabilities and application of virtual instrument technology are continuously improved and play a more efficient role in the more complex measurement environment. Automation level and the level of networking is also continuously improved, R \& D costs and production costs continue to decline, virtual instrument will gradually have the ability to perceive [4]. For example, at the national virtual instrument contest in 2017, a tactile and visual perception somatosensory robot, which is designed by undergraduate students from mechanics institute of Xi'an Jiao tong University School, won the grand prize of the national virtual instrument contest [5].

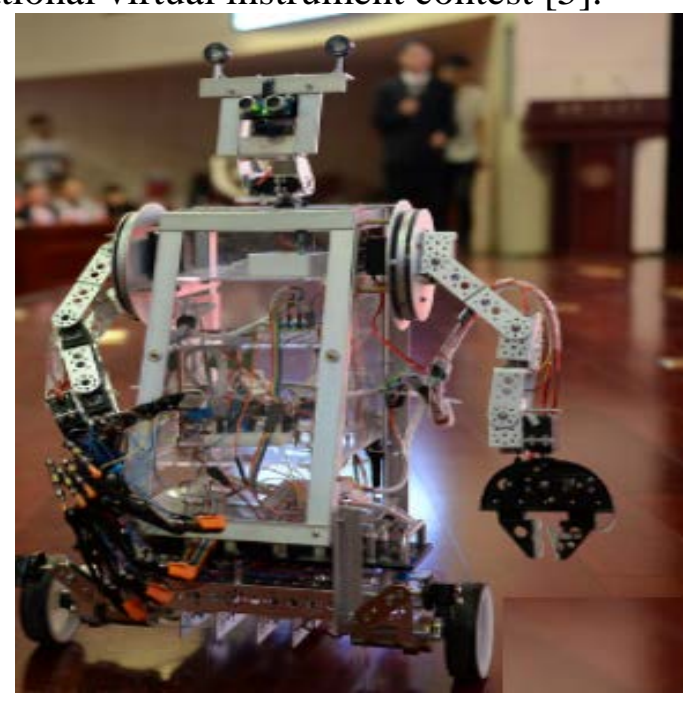

Fig.1 "the somatosensory robot with tactile and visual perception "from mechanics institute of Xi'an Jiao tong University School 
In the functional configuration, virtual instruments improve the defects of traditional measurement instruments, which is single-function. Through the virtual technology, the application area of the instrument and application capabilities are further improved, which can simultaneously complete the measurement, data collection, signal transmission and data display. And with the continuous development of science and technology, the application scope of virtual instrument in the field of electronic measurement expand to further meet people's needs.

Table 1 The advantages comparison of virtual instruments and traditional instruments

\begin{tabular}{cc}
\hline virtual instrument advantages & traditional instruments advantages \\
\hline Flexibility, efficiency, synchronization & Closure,poor compatibility \\
Rely on software, easy to upgrade & Rely on software, inconvenient to upgrade \\
Low price, can be shared & Higher prices, unable to share resources \\
Small size, easy to carry & Large size, inconvenient to carry \\
Function can be customized & Function is single and fixed \\
\hline
\end{tabular}

Table 2 Features contrast of virtual instrument and traditional instruments

\begin{tabular}{|c|c|c|}
\hline Feature & virtual instrument & traditional instruments \\
\hline Openness & $\begin{array}{l}\text { Open and flexible, develop } \\
\text { simultaneously with } \\
\text { information technology }\end{array}$ & Closed and rigid \\
\hline Integration & $\begin{array}{l}\text { Seamless integration of } \\
\text { hardware and software }\end{array}$ & Independent equipment \\
\hline $\begin{array}{l}\text { Development and } \\
\text { maintenance }\end{array}$ & $\begin{array}{l}\text { No need for excessive } \\
\text { maintenance time }\end{array}$ & $\begin{array}{l}\text { Regular maintenance is } \\
\text { required }\end{array}$ \\
\hline
\end{tabular}

\subsection{Obtain real-time detection capabilities}

The organic combination of virtual instrument and monitoring equipment is made to greatly improve the real-time monitoring of virtual instrument. Real-time data acquisition and data transmission are achieved through virtual instrument. The data is recorded and made statistics after transmitted through the sensor. And then the data frequency domain analysis and digital filtering are completed in the shortest possible time, technology processing is made for data, which achieves effective real-time monitoring and real-time processing functions.

Table 3 Basic composition of virtual instrument

\begin{tabular}{cc}
\hline Hardware system & Software system \\
\hline Computers & Control software of instrument panel \\
Standard bus & Signal analysis software \\
I/O interface equipment & Hardware driver software \\
$/$ & Universal I / O interface software \\
\hline
\end{tabular}

During the engineering process, the use of virtual instrument can cover different stages of the project and play a very significant supporting role, including engineering and product development, engineering design and production testing. For example, in industrial production, virtual instrument has many functions such as alarm management, data backtracking, security methods and network 
platform. It can effectively be combined with production processes in industrial production to greatly reduce production costs and improve production quality and productivity.

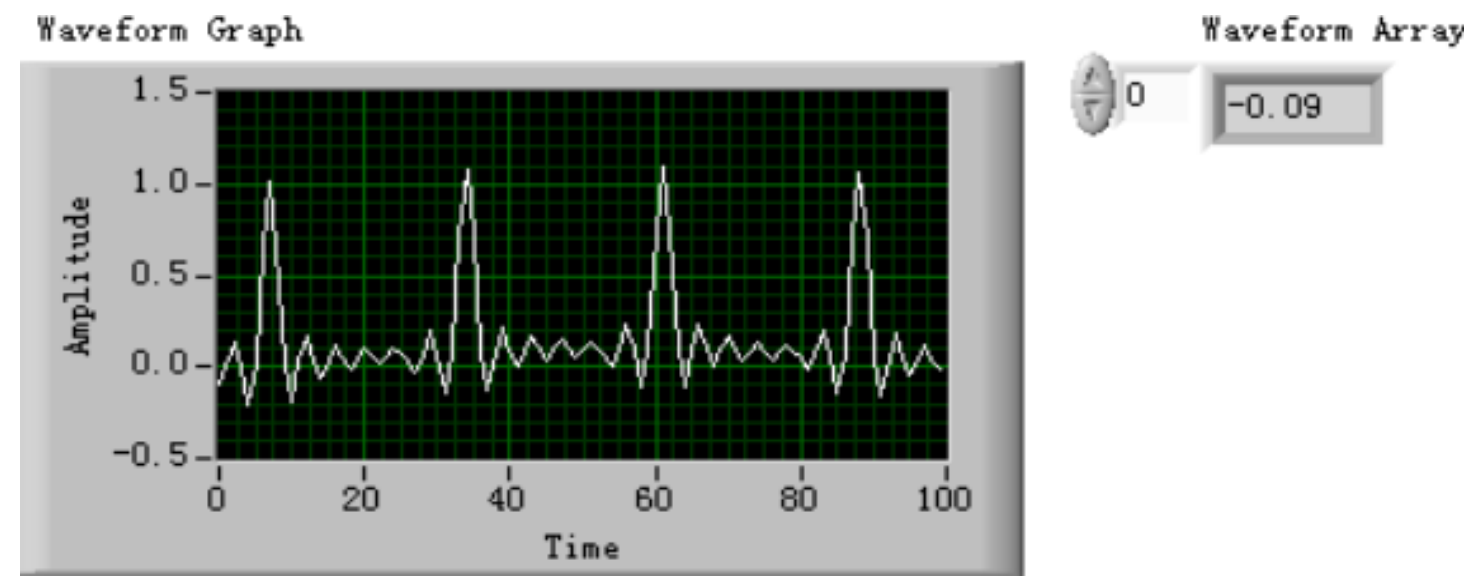

Fig. 2 flow diagram of a project process

Table 4 Virtual instrument features

\begin{tabular}{ccc}
\hline $\begin{array}{c}\text { Acquisition and control } \\
\text { functions }\end{array}$ & Data analysis function & Data display function \\
\hline Output data acquisition & Data signal processing & The internet \\
virtual instrument & Digital filtering & Hard copy \\
VXI & Statistics & File input \\
RS232 & Numerical analysis & Graphical interfaces \\
\hline
\end{tabular}

\subsection{Application in the field of education}

Virtual instrument can also be used in the field of education and teaching, and plays an effective role in reducing the teaching cost investment, integrating teaching resources and improving teaching quality. For example, LabVIEW software development environment has applications in the development of virtual education platform staff. Based on its rich functionality and space, teaching virtual instrument system can be quickly set up. Combined with education and teaching activities, control parts can be reasonably choosing to complete the teaching work.

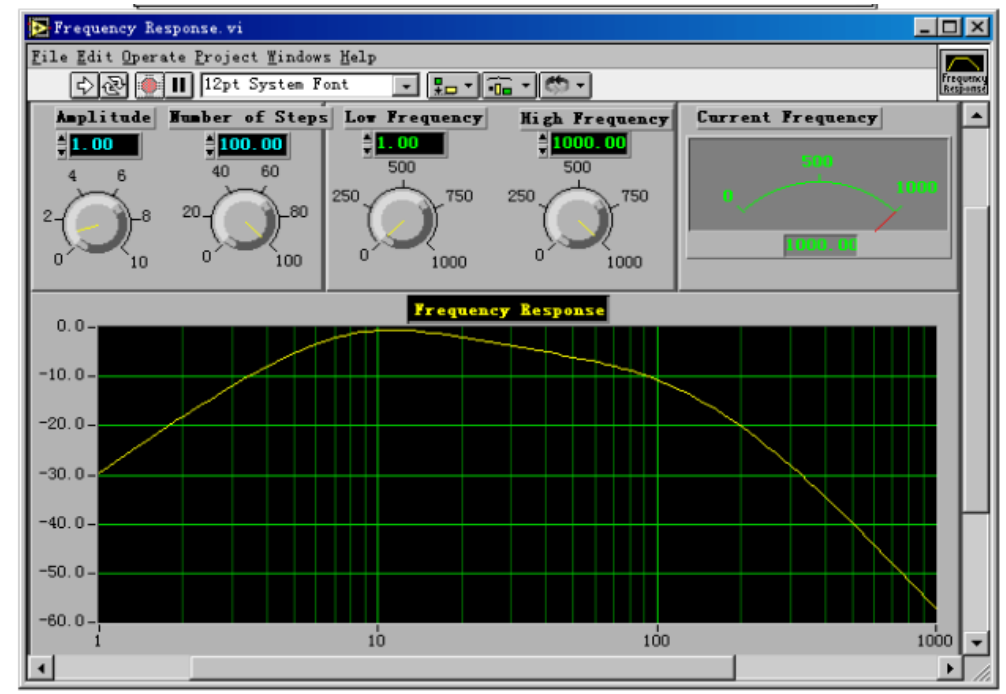

Fig.3 Development environment application interface of LabVIEW software 


\section{The future expectations of technology development of virtual instrument}

\subsection{Standardization development}

Virtual instrument's PCI, VXI, PXI and other technical specifications have gradually realized the standardization and systematization to make normative constraints on the application of technology. However, the virtual instrument's the delay technology, synchronization technology, trigger mode, channel time base and other technical level have not achieved standardized technology applications, resulting in a certain degree of difficulty in the application of technology on different platforms. Poor compatibility, mobility and compatibility will make impacts on the standardization enhancement of virtual instrument technology and equipment. The hardware structure of the virtual instrument will also be gradually standardized and systematized. The standardized development of the module structure will also gradually reduce the popularization of the test system, greatly improve the processing technology of the instrument and further miniaturize the test system.

Table 5 Virtual instrument system software structure

\begin{tabular}{ccc}
\hline $\begin{array}{c}\text { Instrument driving } \\
\text { program }\end{array}$ & I/O interface software & Utility software \\
\hline$/$ & VXI & Database Analysis \\
Software \\
$/$ & GPIB & Instrument panel control \\
software \\
$/$ & Serial & $/$ \\
\hline
\end{tabular}

\subsection{Intelligent development}

Virtual instrument will achieve intelligent development. Software design and instrument manufacturing will gradually achieve organic integration. The existing flaws for virtual instrument are improved in this process. The existing level of virtual instrument technology is relatively high, which cannot meet the needs of users to develop their own at this stage. In addition, virtual instrument $\mathrm{R}$ \& $\mathrm{D}$ design efficiency is low, the existing part of the advanced technology can increase the overlap of software development to some extent. But it still need a lot of software coding work to achieve the integrity of virtual instrument components integration. Through the continuous improvement of the level of intelligence, artificial intelligence can be used to make up for the deficiency of the overlap ability of the virtual instrument, and meet the needs of the user's personalized and customized R \& D [2].

\section{Conclusions}

From the perspective of powerful application advantages of virtual instrument, we should further promote the technology upgrading and development of virtual instrument, and vigorously boost the professional development of virtual instrument research, so as to effectively enhance the role of virtual instrument in the economic development and education of our country.

\section{References}

[1] Yao Y, Ju X, Lu J, et al. Study of virtual instrument technology applied in sound field test[J]. Journal of the Acoustical Society of America, 2016, 139(4):2032-2032.

[2] Jia Z, Li Z, Yang Z, et al. Design and Implementation of a Coal-Bed Methane Fracture Monitoring System based on Virtual Instrument Technology[J]. Instrumentation Science \& Technology, 2015, 43(3):290-302.

[3] Karpouzoglou T, Zulkafli Z, Grainger S, et al. Environmental Virtual Observatories (EVOs): 
prospects for knowledge co-creation and resilience in the Information Age[J]. Current Opinion in Environmental Sustainability, 2016, 18(18):40-48.

[4] Zolfaghari R, Shrivastava Y, Agelidis V G. Evaluation of windowed ESPRIT virtual instrument for estimating Power Quality Indices[J]. Electric Power Systems Research, 2012, 83(1):58-65.

[5] Tychkov A Y, Abrosimova O V, Kuz’ Min A V. Development in the Lab View Environment of a Virtual Instrument for Noninvasive Measurement of Arterial Pressure[J]. Measurement Techniques, 2015, 58(9):1062-1065. 